\begin{tabular}{|l|l|l|l|l|l|l|}
\hline InterteXto & Uberaba & UFTM & $\begin{array}{l}\text { v. } 2 \\
\text { n. 3 }\end{array}$ & p. 54-76 & 2009 - jan. / jun. & ISSN 1981-0601 \\
\hline
\end{tabular}

\title{
EDUCAÇÃO E IDENTIDADE: DESENCONTROS NA FORMAÇÃO DE PROFESSORES DE LÍNGUAS
}

\author{
EDUCATION AND IDENTITY: MISMATCHES IN LANGUAGE \\ TEACHERS TRAINING COURSES
}

\begin{abstract}
Albeiro Mejia Trujillo ${ }^{1}$
\section{Resumo}

No presente artigo aborda-se a formação de professores de línguas tendo-se como ponto de referência a noção de desconstrução, como entendida pelo autor deste texto. Aponta-se a necessidade de desconstruir as ideologias que se instalam nas diversas instâncias da formação de professores de línguas por entender que o contexto educativo não escapa aos influxos que determinam a formação da cultura e da identidade nos diversos níveis de organização social. Destacam-se, ainda, alguns componentes polêmicos na formação de professores de Línguas como a falha nas diretrizes governamentais para os Cursos de Letras; o grande descompasso entre o primado dos estudos literários por oposição à limitada quantidade de estudos avançados em áreas específicas da Lingüística e, ainda, o desencontro entre as linhas teóricas da Lingüística em sua franca oposição aos domínios específicos de estudo do fenômeno da linguagem. O contexto teórico deste artigo busca mostrar que a formação de professores de línguas tem de estar atrelada a outros domínios do conhecimento humano para poder abordar a língua na sua complexidade como elemento constitutivo da cultura e consolidador da identidade das nações.
\end{abstract}

Palavras-chave: Desconstrução; Identidade; Lingüística; Ideologia; Cultura.

\begin{abstract}
This article discusses the training courses of language teachers. It has as a reference point the notion of deconstruction, as understood by the author of this text. It is pointed the need of deconstructing the ideologies established in the various language teachers training courses because the educational context does not escape the inflows that determine the formation of culture and identity at various levels of social organization. It is also presented some polemic components in the language teachers training courses, such as failure in government guidelines for courses of Linguistics, the large gap between the primacy of literary studies in opposite of the limited amount of advanced studies in specific areas of linguistics and also the mismatch between the lines of theoretical linguistics in opposition to specific areas of study of the language phenomenon. The theoretical context of this paper shows that the language teachers training courses must be linked to other areas of human knowledge in order to study the language in its complexity as a constitutive element of culture and as identity consolidator of nations.
\end{abstract}

\footnotetext{
${ }^{1}$ Coordenador do ISE/Filosofia do Instituto de Ensino Superior do Centro Oeste - IESCO. malbeiro@yahoo.com.br; albeiro@iesco.edu.br
} 


\begin{tabular}{|l|l|l|l|l|l|l|}
\hline InterteXto & Uberaba & UFTM & $\begin{array}{l}\text { v. } 2 \\
\text { n. 3 }\end{array}$ & p. 54-76 & 2009 - jan. / jun. & ISSN 1981-0601 \\
\hline
\end{tabular}

Keywords: Deconstruction; identity, Linguistics, Ideology, Culture.

A Educação como objeto de estudo da Ciência da Linguagem assume o papel de formadora de agentes que ajudam nos processos de construção da identidade nos diferentes segmentos globais das organizações sociais. A Lingüística no processo de formação de professores de línguas deverá superar os limites dos discursos meramente pedagogizantes e incursionar em áreas que lhe proporcionem novas perspectivas de análise mediante os diálogos interdisciplinares. Durante a segunda metade do século XX surge, na Europa, uma corrente de pensamento que recebe o nome de "Desconstrucionismo" e que será desenvolvida, não somente nas Ciências Humanas, mas também nas Ciências Sociais Aplicadas, Ciências Médicas e Biológicas e; por isso, encontramos tentativas desconstrucionistas na Filosofia, Literatura, Pedagogia, Lingüística, Psicologia, Ciências Jurídicas, Antropologia, Sociologia, Comunicação e; nos diversos campos da Biologia, Física, Química, Medicina (Genética) etc. O Desconstrucionismo nesses contextos não tem a idéia de um pantoclastismo cuja finalidade é a destruição (não justificada) do que existe; mas inserir aquilo que participa de uma ordem sistêmica e estrutural, em um processo de ajustes que permita ter acesso à compreensão e dar relevância prática (utilidade) às esferas sociais, tendo na Educação um dos maiores instrumentos de expansão da cultura que conduz à construção da Cidadania e à afirmação da(s) identidade(s).

O anacronismo pelo qual tem passado a área de formação de professores de línguas, no sentido de receber as idéias geradas em outros domínios do saber até com um século de atraso se deve, em parte, à falta de percepção de que a língua enquanto mecanismo de produção de saberes e instrumento de manifestação da cultura tem o poder de desconstruir e destruir, alienar e reificar povos inteiros na medida em que mostra os modos de existência dos entes possuidores de uma identidade cujo arcabouço se encontra na história de cada nação, já que a língua e a cultura não são 


\begin{tabular}{|l|l|l|l|l|l|l|}
\hline InterteXto & Uberaba & UFTM & $\begin{array}{l}\text { v. } 2 \\
\text { n. 3 }\end{array}$ & p. 54-76 & 2009 - jan. / jun. & ISSN 1981-0601 \\
\hline
\end{tabular}

expressão de um sujeito isolado, embora cada indivíduo manifeste a sua percepção da língua e da cultura de uma maneira peculiar e única.

O processo desconstrucionista vivido na América Latina nos apresenta uma fase positiva e outra negativa. A primeira, parte de um nada como potência e, a segunda, tem como base a existência de um não-ser. Ao colocar o nada como potência e possibilidade, parte-se do pressuposto de que um existente possa ter sua estrutura modificada e, para isso, é necessário desconstruir o ser atual para que o ainda-não, que constitui aquilo a que o nada dará existência, possa acontecer direcionando o vir-a-ser que está em processo de formação. Mesmo que se tivesse afirmado que o Índio não era humano porque não tinha alma, por não haver sido batizado, não se estava negando a possibilidade de que pela catequese e o batismo, viesse a se transformar em Cristão (humano); tendo assim uma desconstrução positiva, porque parte de um nada (ainda-não) ou potência, para re-construir ou dar forma a um existente, modificando-o, porém, sem destruí-lo, nem negá-lo.

A desconstrução negativa que se funda na negação de um existente como "não-ser" não vê possibilidades de erigir um pré-existente, já que somente um "ser" pode gerar outro "ser" e; o não-ser deverá ser extinto para libertar - destruir o outro que se opõe a meu existir. A imagem pré-concebida do outro gera o preconceito (negativo), que afirma a negação do alter como não-ser e, não-ser é menos que nada, já que este é possibilidade e potência, enquanto aquele é negação de toda possibilidade de vir-a-ser, passando pelo ignorar o outro que constitui um ato de violência simbólica que carrega um potencial maior de crueldade do que a própria agressão física. Esta coloca duas existências antagônicas em pé de igualdade porque a vontade de matar o outro constitui a afirmação do mesmo, porque me incomoda. Ignorar ou "não ver" o outro caracteriza a negação absoluta do mesmo, pois não se reconhece nele valor algum, nem sequer uma possibilidade por mais distante e obscura que seja. Algo que se ignora, que não existe nem como possibilidade, somente pode ser visto como um não-ser, que é a negação de qualquer potencialidade e 


\begin{tabular}{|l|l|l|l|l|l|l|}
\hline InterteXto & Uberaba & UFTM & $\begin{array}{l}\text { v. } 2 \\
\text { n. 3 }\end{array}$ & p. 54-76 & 2009 - jan. / jun. & ISSN 1981-0601 \\
\hline
\end{tabular}

é o que acontece, de modo geral, com os chamados países periféricos. Quando não se vê neles pelo menos uma possibilidade existencial, não é possível que sejam colocados num processo de desconstrução porque isso implicaria que estaríamos vendo estruturas e sistemas em um objeto de nossa negação e que necessariamente terá de ser destruído.

Afirmar uma filosofia latino-americana ou uma literatura legitimamente africana implica na afirmação da identidade daquele "outro" que tem sido objeto do não-ser ao longo dos séculos, fato que nos permite entender a resistência canônica contra certas formas literárias de países do Leste Europeu, da África, do Oriente Médio, além de grande parte da América Latina. A distinção entre Desconstrução positiva e negativa parece simples, todavia, o produto gerado num processo de desconstrução positiva não somente busca a afirmação identitária do objeto desconstruído, mas, geralmente, busca eliminar o que é, para gerar algo que não o mesmo. Isso implica em afirmar que a dita desconstrução positiva, mina as bases do ser desconstruído, alterando sua essência e firmando uma destruição categorial, chegando ao não-ser através de uma suposta valorização das potencialidades do ainda-não expressas no nada. A desconstrução quando entendida como compreensão permite-nos caminhar em direção a uma re-construção e, nesse caso, não estaríamos fugindo do sentido inicial da desconstrução positiva.

Reconstruir, portanto, não significa voltar ao elemento que nos serviu de ponto de partida, pois essa reconstrução pode ser, na verdade, uma nova construção do mesmo que não foi desconstruído, senão destruído. Se pensarmos no processo de colonização, como aconteceu na América Latina, fica claro que foram mantidos os modelos sistêmicos das comunidades indígenas; mas as estruturas íntimas foram totalmente alteradas produzindo como resultado, não uma reconstrução, depois de alcançar a compreensão através de um mecanismo desconstrucionista, senão que houve uma nova construção sobre as bases de algo que havia sido destruído e não desconstruído. Assim, a desconstrução positiva, transformou-se em negativa, 


\begin{tabular}{|l|l|l|l|l|l|l|}
\hline InterteXto & Uberaba & UFTM & $\begin{array}{l}\text { v. } 2 \\
\text { n. 3 }\end{array}$ & p. 54-76 & 2009 - jan. / jun. & ISSN 1981-0601 \\
\hline
\end{tabular}

devido aos procedimentos desvendados pelo sistema hermenêutico. A Educação que deveria contribuir, por intermédio da desconstrução, para a formação de novas perspectivas sociais capazes de erigir mecanismos de compreensão e ação grupal, vem-se mostrando instrumento de reconstrução do mesmo, negando as possibilidades de colocar os alicerces da identidade lingüística e cultural.

Se, por outro lado, analisarmos a implosão de um edifício como o do presídio "Carandiru", poderíamos ver nessa implosão (destruição de um prédio físico), que a desconstrução das superestruturas leva à compreensão de uma realidade insustentável que deverá ser destruída, somente que essa destruição não representa o fim do sistema penitenciário nem das superestruturas vigentes na justiça nacional. Nesse caso particular acontece uma reconstrução das estruturas, com modificações que alteram a forma e condições de funcionamento do presídio e a destruição de um prédio não representa o fim dos presídios, mas a compreensão de que deve ser alterada sua estrutura. Reconstrói-se o presídio, mantêm-se os detentos, não muda o sistema jurídico, mas houve uma compreensão que passou por uma desconstrução em que a destruição constitui uma mudança na forma da prisão, não eliminou o objeto de destruição, permitindo uma "re-construção do mesmo", sem eliminar o essencial, mas ativando as potencialidades do nada, no sentido de tornar visível e chamar a atenção para a possibilidade real de mudanças conscientes em qualquer esfera social.

O processo de formação de professores de línguas precisa ser desconstruído para poder restituir-lhe seus sentidos alienados como conseqüência de ideologias ou simples pseudo-teorias que em nome de uma valorização e respeito dos elementos sociolingüísticos terminam condenando o próprio povo à exclusão. Do ponto de vista das ações políticas, talvez a Filologia Românica, enquanto disciplina, seja somente um exemplo significativo da displicência por parte dos órgãos de fomento à formação de professores de nível superior, pois, na ausência de profissionais dessa área mencionada, as 


\begin{tabular}{|l|l|l|l|l|l|l|}
\hline InterteXto & Uberaba & UFTM & $\begin{array}{l}\text { v. } 2 \\
\text { n. 3 }\end{array}$ & p. 54-76 & 2009 - jan. / jun. & ISSN 1981-0601 \\
\hline
\end{tabular}

diretrizes para os Cursos de Letras sugerem a exclusão desse conteúdo da formação de professores de Letras quando as políticas corretas deveriam apontar para um maior investimento na criação de linhas de pesquisa que estimulassem a formação de novos filólogos. A Filologia é somente um exemplo, porque o descompasso entre a quantidade de programas de pósgraduação em literatura com as reais necessidades de formação de especialistas de outros domínios lingüísticos chega a ser preocupante.

Maior gravidade representa a percepção de que ideologias marxistas anacrônicas tomaram conta de certos setores da lingüística em que uma tese de doutorado transformada em livro sobre "Preconceito Lingüístico" se tornara uma referência nacional, não em "pesquisa", senão em discursos lingüísticos que assumem autodenominações de sociolingüística, análise do discurso, neuro e psicolingüística etc. A polarização entre lingüística teórica (retórica) e pragmática lingüística representa um retrocesso para a ciência da linguagem e um entrave para a formação de professores de línguas, já que, a primeira, posiciona-se contra os sistemas de gramaticalização como se a gramática descritiva que apresenta as estruturas fonético-fonológicas, lexicais, morfológicas, sintáticas, semânticas e semiológicas não fizesse parte de seus domínios de estudo. Esse direcionamento que está sendo dado a muitos cursos de Letras, no Brasil, está formando uma geração de professores que ao estudar Lingüística, pensam estar entrando em um domínio "reflexivo" antagônico ao fenômeno dos contextos constitutivos da língua e, por isso, apresenta-se a emergência da desconstrução dos mecanismos de formação de professores de línguas, que devem ser direcionados para processos de descoberta e fixação da identidade lingüística e cultural.

A desconstrução negativa manifesta no não-ser como negação de um existente, quando tenta negar o outro, termina afirmando-o. Na dialética do Senhor e do Escravo, o primeiro somente existe porque tem o segundo que the permite afirmar-se como tal e; por sua vez, o Escravo quando é castigado e deseja a morte do Senhor, sente e toma consciência de que a sua existência é 


\begin{tabular}{|l|l|l|l|l|l|l|}
\hline InterteXto & Uberaba & UFTM & $\begin{array}{l}\text { v. } 2 \\
\text { n. 3 }\end{array}$ & p. 54-76 & 2009 - jan. / jun. & ISSN 1981-0601 \\
\hline
\end{tabular}

necessária para a sobrevivência do outro, tornando as tentativas de negação e morte, em mecanismos de mútua afirmação. Ver o outro como um não-ser constitui um sistema de negação do outro como "eu", mas leva à afirmação do não-ser-eu, em um ser eu-alter. Isso nos coloca diante de uma desconstrução que, por negar afirma: não como "o mesmo", mas como "outro eu" do qual, quer queira, quer não, passo a depender, tendo como principal manifestação o estranhamento que conduz às diversas formas de violências. Talvez os movimentos afro-descendentes estejam passando por esses processos de afirmação negativa, no sentido que por negar o outro (branco) como mecanismo de auto-afirmação, terminam negando-se a si mesmos como meramente humanos que é a característica comum que deveria prevalecer entre as sociedades.

A desconstrução negativa nega, porém, não destrói, pois ao ignorar, tem-se na frente não uma potência ou possibilidade que pode ser alterada ou destruída, senão uma realidade material ou ideal, em que pese a vontade de que não exista aí, continua a incomodar porque ocupa um espaço que poderia ser a minha própria existência. Mostrar que o outro é um não-ser, negando sua existência, leva à conclusão de que estamos diante de um não-ser-eu, que afirma esse não-ser-eu, como um ser-alter e; para chegar a tal noção precisamos desconstruir o alter que estamos negando, somente que só se pode desconstruir algo que possui uma existência material ou ideal. Todavia, como negar algo que não existe quando seu "Ser" é o objeto da desconstrução, sendo que, se o "não-ser" existe, posso desconstruí-lo para ter a compreensão do seu ser e; na re-construção haverá a restituição da existência e o reconhecimento do outro como um alter que é um "eu" que não "eu", chegando finalmente à aceitação de uma existência plural que se desenvolve dentro de contextos de Identidades múltiplas.

As tentativas de desconstrução são exploradas por intermédio do "imaginário coletivo", somente que este conceito deverá ser repensado, já que os desconstrucionistas apelam a ele, e não à imaginação individual, como 


\begin{tabular}{|l|l|l|l|l|l|l|}
\hline InterteXto & Uberaba & UFTM & $\begin{array}{l}\text { v. } 2 \\
\text { n. 3 }\end{array}$ & p. 54-76 & 2009 - jan. / jun. & ISSN 1981-0601 \\
\hline
\end{tabular}

instrumento de trabalho sem saber se existe algum elo que mantenha a cadeia de idéias singulares e coletivas vinculadas ou, se estas, acontecem de modo independente. O gênero, a raça, a política, a miscigenação, a justiça são alguns elementos objeto de "desconstrução", somente que o foco desta, parte do coletivo e não busca raízes desse imaginário coletivo nas construções singulares. Em muitos casos valida-se o imaginário coletivo como um processo sociocultural que acontece de modo natural, enquanto o imaginário particular é vitimado pelas interdições que vêem no singular, simples manifestações patogênicas.

Seja qual for o conjunto de idéias e a compreensão que se tenha de uma dada realidade, cada sujeito particular constrói um mundo singular e inacessível que podemos tentar compreender, não, porém, explicá-lo sob critérios positivistas. As imaginações, como ocorrem no processo lógico, depois de formular seus conceitos, exterioriza-os utilizando para tal as linguagens que estiverem ao alcance dos indivíduos que estão de posse de uma realidade transformada no interior do sujeito, em imaginário singular. Não se forma, então, um imaginário coletivo sem o a priori de razões (mentes) que ao exteriorizar suas imagens, misturam-se com outras percepções. Muitas destas encontrarão afinidades ou contradições e, esse jogo de semelhanças e diferenças mostrará como podemos encontrar manifestações culturais bastante parecidas em lugares distantes entre se, ou, pelo contrário, elementos culturais totalmente diferentes entre grupos próximos.

Por vezes, esse jogo de diferenças e semelhanças tem levado a que grupos diversos combinem, como numa caldeira, os mais diversos elementos, dando origem a um novo produto que será o resultado de elementos vários, mas que no novo formato será reconhecido como algo diferente que a coletividade passará a valorizar sem questionar origem, veracidade, autoria, mas o que interessa é que o surgimento desse "algo" diferente já faz parte real da expressão imaginária de uma coletividade. O que eram idéias e concepções particulares quando encontra diversos sujeitos que se identificam com formas 


\begin{tabular}{|l|l|l|l|l|l|l|}
\hline InterteXto & Uberaba & UFTM & $\begin{array}{l}\text { v. } 2 \\
\text { n. 3 }\end{array}$ & p. 54-76 & 2009 - jan. / jun. & ISSN 1981-0601 \\
\hline
\end{tabular}

semelhantes de agir e pensar se constitui no imaginário coletivo que será orientado por uma série de valores; crenças; postulados; atitudes que, no inconsciente de cada membro da sociedade terá repercussões na formação da personalidade e da identidade.

Sem pretender fazer uma genealogia da formação identitária de indivíduos e grupos; descobrimos que, se começarmos a explicar o imaginário coletivo pelo singular ou a identidade sociocultural da qual fazem parte os indivíduos singulares e coletivos, estaremos criando o mesmo paradoxo hobbesiano e rousseauniano em que, segundo o primeiro, é o homem enquanto átomo isolado que dá origem à sociedade e; conforme o segundo, a coletividade já existe pronta para receber cada novo homem natural sem questionar a origem dessa sociedade, só se sabe que o contrato social acontece entre um indivíduo que nasce e a sociedade que o acolhe. Para tentar fugir do paradoxo do imaginário individual e o coletivo, arriscamos afirmar que: embora o particular beba hoje na fonte do coletivo, não é possível formar um coletivo que não parta do individual, e isso pode ser fundamentado pela Física que nos ajuda a entender a energia fluida como a base da formação dos átomos que, ao se juntarem, dão origem à matéria que segundo as condições de organização apresentam características diversas.

Se os desconstrucionistas, positivos ou negativos, tentam negar ou destruir o outro utilizando a ideologia que foi colocada como base de formação do imaginário coletivo é evidente que não se está a falar de desconstrução como nada (positiva) ou como não-ser (negativa), para entender e "re-construir o mesmo" respeitando sua identidade; mas se está falando de uma tentativa perversa e desigual de destruir o outro de dentro para fora. O perigo do imaginário coletivo radica no fato dele possuir na sua própria estrutura a fonte de destruição, que não a utilizaria se não fosse manipulada por agentes externos que, neste caso, são os supostos desconstrucionistas agindo como destruidores que não estão interessados em compreender; mas têm por 


\begin{tabular}{|l|l|l|l|l|l|l|}
\hline InterteXto & Uberaba & UFTM & $\begin{array}{l}\text { v. } 2 \\
\text { n. 3 }\end{array}$ & p. 54-76 & 2009 - jan. / jun. & ISSN 1981-0601 \\
\hline
\end{tabular}

missão, minar as bases da "existência - outra" para destruí-la, servindo-se do imaginário coletivo como explosivo ou veneno que leva à autodestruição.

Desde a segunda metade do século XIX, e até a década de 1970 havia pensadores preocupados com o "Ser" latino-americano em todos seus aspectos, e com a construção de uma identidade que unificasse as nações da América Latina. Esse projeto que no Brasil encontra expressão significativa em escritores como Lima Barreto e, posteriormente em Mário de Andrade, mostra o início de seu esmorecimento quando Triste Fim de Policarpo Quaresma e Macunaíma, respectivamente, passam a ser vistas como simples obras características de um estilo cômico pândego cuja única finalidade era a folclorização de setores da sociedade e, não como a busca da expressão de identidades plurais. Além de não surgirem novos intelectos significativos dispostos a pensar o "ser" numa perspectiva filosófico-cultural aqueles que defendiam a existência de uma filosofia autóctone ou pelo menos a partir da terra mãe, terminam sendo absorvidos por discursos sociológicos, econômicos, políticos, etnográficos, religiosos ou ideológicos.

Expor um pensamento latino-americano que represente uma expressão de autenticidade e identidade, certamente trará consigo reações em que essa tentativa seja chamada de simples anacronismo. Defender a retomada de uma unidade nacional e não por camadas sociais particulares, talvez seja 0 resultado da esperança que ainda resta no ressurgir da Fênix, ou do poder de transformação da própria razão. Esta não deve conduzir ao fanatismo ou à desesperança, mesmo que tenha sido ofuscada pelos inúmeros reflexos da realidade que a encobriram. Sabe-se que na atualidade existem limitações, na América Latina, quanto à produção de um pensamento original como resultado, em parte, dos processos de globalização e; mesmo que essa afirmação doa, a razão obriga a aceitá-la, o que não quer dizer que o legado de mais de um século de trabalho de grandes arautos da integração e da identidade continental esteja sepultado para sempre. 


\begin{tabular}{|l|l|l|l|l|l|l|}
\hline InterteXto & Uberaba & UFTM & $\begin{array}{l}\text { v. } 2 \\
\text { n. 3 }\end{array}$ & p. 54-76 & 2009 - jan. / jun. & ISSN 1981-0601 \\
\hline
\end{tabular}

O fracasso na tentativa de cultivar a identidade dos diversos povos tem causas tanto internas quanto externas. Fenômenos como a globalização, a formação de blocos econômicos, o surgimento e desmoronamento de regimes políticos, a secularização por oposição ao fanatismo religioso, a abertura total da comunicação e o livre saber, o desenvolvimento tecnológico, o intervencionismo nos sistemas políticos nacionais, a imposição de uma cultura de massas altamente invasiva são somente alguns elementos externos que interferem diretamente sobre a idéia de criar uma unidade supranacional de natureza histórico-cultural e conduz a uma separação não somente internacional, mas também, e sobre tudo, um processo de divisão etno-cultural intra-nacional.

As causas externas que levaram ao fenecimento das tentativas de criar uma unidade de pensamento e de identidade, na América Latina, são elementos que embora agindo de modo direto, devem ser considerados fatores agregados e complicadores de um processo que já se vinha manifestando no interior dos países e blocos de países das regiões do continente americano (América Central e América do Sul). Interessa-nos abordar os elementos internos, mais do que os externos, já que estes últimos são difusos e não podem ser considerados como causas diretas e exclusivas das mudanças culturais. O processo de colonização teve características diferentes nas diversas regiões da América Latina e o Caribe, sendo que em alguns dos territórios houve ações de intenção exterminatória das populações locais e, em outros, o agir foi predatório com substituição da mão de obra nativa pela força de trabalho escrava provinda do continente africano.

Os povos que perderam seus territórios e conseguiram fugir do assassínio tiveram de se refugiar em áreas de difícil acesso e pouco interesse para os colonizadores. Os grupos indígenas aparentemente conseguiram manter uma unidade étnica e cultural, mas a unidade aqui referida como aparente, na verdade constitui expressão manifesta de uma miscigenação, onde o elemento branco dilui-se nas matizes dos povos nativos. $O$ 


\begin{tabular}{|l|l|l|l|l|l|l|}
\hline InterteXto & Uberaba & UFTM & $\begin{array}{l}\text { v. } 2 \\
\text { n. 3 }\end{array}$ & p. 54-76 & 2009 - jan. / jun. & ISSN 1981-0601 \\
\hline
\end{tabular}

remanescente originário no século $X X$ aponta para a extinção de grupos indígenas quando o que está desaparecendo são as línguas, tradições culturais e a identidade dos povos sobreviventes aos processos de massificação cultural, mas a predominância nativa (miscigenada), em países como México, Equador, Bolívia, Peru, Uruguai, Paraguai e outros com protótipos étnicos mais diversificados como a Colômbia e Nicarágua é evidente, daí vermos com estranheza a idéia de extinção do elemento étnico nativo quando países como o Paraguai utiliza no dia-a-dia mais o guarani ou uma mescla de guarani com espanhol do que a própria língua espanhola convencional; ou o Equador que utiliza o Quíchua ou este combinado com o espanhol, mas dificilmente se fala só espanhol, diferentemente da maioria dos países latino-americanos.

As áreas de predominância afro-descendentes são mais fortes nas llhas do Caribe e em países como Costa Rica, República Dominicana, El Salvador, Venezuela, regiões do Caribe e do Pacífico colombiano, minorias negras do pacífico equatoriano que mal superam meio milhão de habitantes. A miscigenação das raças negra e branca nessas áreas, com exceção do Equador, tornou-se uma constante, motivo pelo qual a fusão cultural atingiu níveis tão elevados que não permitem dizer o que é cultura branca e o que é cultura negra, tornando imperativo o uso do conceito de hibridismo cultural sem destaque para uma raça em particular, pois, a América Latina, dividida principalmente nesses dois processos miscigenatórios, tem dificuldades para definir a sua identidade. Enquanto a Bolívia tenta resgatar a identidade originária, da dominação branca; Costa Rica (entre outros) luta pela emancipação da população negra, do jugo branco. As reivindicações tendentes à reparação do passado, concretizam-se em ações, no Brasil, como a criação de cátedras sobre afro-descendência e atribuição de benefícios mediante a concessão de quotas para ingresso nas universidades e em concursos públicos.

Em um cenário em que praticamente a Argentina e os três Estados do sul do Brasil poderiam ser considerados locais de menores índices de mistura 


\begin{tabular}{|l|l|l|l|l|l|l|}
\hline InterteXto & Uberaba & UFTM & $\begin{array}{l}\text { v. } 2 \\
\text { n. 3 }\end{array}$ & p. 54-76 & 2009 - jan. / jun. & ISSN 1981-0601 \\
\hline
\end{tabular}

racial e permanência da raça branca, parece absurdo que os países latinoamericanos estejam se digladiando em lutas raciais contra o elemento branco, inimigo comum de afro-descendentes e descendentes dos povos nativos; e que praticamente inexiste com formas claras de serem definidas, sendo que os chamados brancos, donos do poder, são os mesmos miscigenados que, quando convém, são brancos e quando os interesses políticos e econômicos são maiores, adotam um discurso em defesa dos povos originários ou então das populações negras e afro-descendentes.

O movimento reivindicatório negro tem ganhado força e seguidores em numerosos segmentos da população organizada que não se tem manifestado com o mesmo ímpeto entre as camadas descendentes dos povos originários. $O$ fenômeno de reivindicação dos direitos raciais, presente no início do século $\mathrm{XXI}$, na América Latina, preocupa pelo viés discriminatórios às avessas que vem apresentando, haja vista que, pelo menos $95 \%$ da população deste segmento do continente americano é resultado de algum tipo de processo miscigenatório; sendo assim, a maioria das classes dominantes são expressão de um conjunto de mesclas étnicas e, ao somar a participação por cotas nas diversas esferas da sociedade, cria-se uma situação discriminatória às avessas. A luta do segmento da população negra contra "os brancos" é uma batalha que, na América Latina, está carregada de sentimentos de ódio e raiva, sendo que a discriminação racial contra brancos também existe e não com menos intensidade.

Enquanto os sinais de falta ou de conflito de identidade avançam, o racismo negro toma proporções de intolerância que se mantêm escondidos porque poucos brancos ousariam ir até uma delegacia de polícia denunciar um negro por discriminação racial. Os guetos e as chamadas irmandades negras são legais e legítimas, restringindo o ingresso de brancos a essas organizações, no entanto, uma tentativa de agrupamento branco que restringisse o ingresso de negros tomaria proporções de violação dos direitos humanos com denúncia do país que permitisse essas organizações às 


\begin{tabular}{|l|l|l|l|l|l|l|}
\hline InterteXto & Uberaba & UFTM & $\begin{array}{l}\text { v. } 2 \\
\text { n. 3 }\end{array}$ & p. 54-76 & 2009 - jan. / jun. & ISSN 1981-0601 \\
\hline
\end{tabular}

instituições de direito internacional. Daí termos que é perfeitamente legítimo falar da constituição do Parlamento Negro das Américas, no seio da Confederação Parlamentar das Américas - COPA, porém, não se pode nem cogitar a criação de um parlamento branco regional.

A definição e caracterização de quem é branco, negro, originário ou, no caso da miscigenação, saber quem continua a ser classificado como branco, afro-descendente, ou descendente dos povos originários é uma tarefa impossível e alcança um nível de subjetividade e relativismo tal que provoca a transposição de uma discussão etnológica para o campo ideológico. Falar de cultura "afro", na América Latina, constitui um reducionismo absurdo que somente reflete o desconhecimento generalizado dos modos e costumes, crenças e ritos, geografia física e humana etc., que os povos da América têm quando se referem ao Continente Africano, como se este fosse uma unidade. Um exemplo mínimo, porém claro, das diferenças e da variedade cultural existente no continente africano, pode-se encontrar em países como Ruanda, na África Central, onde convivem três etnias tão diversas que; mesmo sendo negros, moradores de um mesmo território, suas diferenças intransponíveis deflagraram em 1994 uma guerra com um saldo de mortos que superou um milhão e deixou um altíssimo numero de aleijados na população.

Se as diferenças entre os moradores de um mesmo país, como o caso de Ruanda, de uma mesma raça, mas de etnias diferentes; sem um passado de dominação como a que aconteceu no período de colonização da América Latina, gera relações tão polares, poderíamos dizer que não são as diferenças raciais as responsáveis pelos conflitos entre as nações e grupos sociais, senão que fundamentalmente a política e a economia são as responsáveis pelas desavenças no mundo ao longo da história. Colocar a raça como responsável pelos conflitos na América Latina constitui estreiteza de visão histórica e desconhecimento da realidade etno-cultural africana que se pretende defender. O contexto negro latino-americano tem muito pouco de africano, tornando-se um apelo meramente circunstancial e de interesses ideológicos. 


\begin{tabular}{|l|l|l|l|l|l|l|}
\hline InterteXto & Uberaba & UFTM & $\begin{array}{l}\text { v. 2 } \\
\text { n. } 3\end{array}$ & p. 54-76 & 2009 - jan. / jun. & ISSN 1981-0601 \\
\hline
\end{tabular}

Com propostas como a criação de um Parlamento Negro das Américas, chegamos perto da deflagração de uma crise do tipo apartheid semelhante à vivida na África do Sul. O foco é político e não étnico e a solução a um problema real está sendo buscada a partir do sentimento de inferioridade cultivado durante séculos por setores da sociedade, quando a solução aos problemas tem de ser de natureza econômica e cultural não excludente. A discriminação em forma de racismo, na América Latina, acontece em todos os níveis étnicos onde o elemento determinante da exclusão é o financeiro. Países como o Equador, Bolívia, Peru, Uruguai sofrem uma carga discriminatória no contexto internacional, mostrando-se como causa desse fenômeno a tipologia racial predominante quando, na verdade, o fator preponderante no processo de exclusão é a relativa baixa participação no mercado mundial e os modelos de formação econômica que projetam uma situação financeira altamente instável. A má distribuição da renda espelhada nos focos de miséria, aparentemente tem como vítimas as comunidades originárias e como responsáveis os brancos, mas se a população é altamente miscigenada, o elemento branco é insignificante $\mathrm{e}$ as elites dominantes são constituídas pelos próprios descendentes dos povos originários que não se reconhecem na cultura local.

O discurso político de países como a Venezuela, Costa Rica e Cuba, é de igualdade social, prosperidade e racionalidade das esferas da sociedade. Esses três países que apresentam uma tipologia racial negra predominante e altos níveis de miscigenação adotaram discursos que pretendem mostrar aos demais países latino-americanos que são paraísos onde a educação alcançou o maior nível de desenvolvimento, com a total erradicação do analfabetismo (é o caso de Cuba que se orgulha ao afirmar que tem escolas para atender a um único aluno); a saúde atingiu médias que chegam a uma média de um médico para cada quinze habitantes. Se esses dados são verdadeiros ou se constituem mero discurso ideológico dos parlamentares desses países mencionados, em eventos internacionais como o da Confederação Parlamentar das Américas - COPA, somente esses países poderão dizê-lo. Tais dados 


\begin{tabular}{|l|l|l|l|l|l|l|}
\hline InterteXto & Uberaba & UFTM & $\begin{array}{l}\text { v. } 2 \\
\text { n. 3 }\end{array}$ & p. 54-76 & 2009 - jan. / jun. & ISSN 1981-0601 \\
\hline
\end{tabular}

levam-nos a confirmar a hipótese de que o problema da discriminação e desigualdade na América Latina não é um problema de cor da pele e sim um caso de institucionalização política da pobreza que afeta a todos os sujeitos da classe baixa, independentemente da cor. A miséria é uma boa fonte de dinheiro e os discursos racialistas e de gênero servem para a promoção de políticas de base populista.

Muitos dos chamados países emergentes digladiam-se e utilizam discursos anti-imperialistas ultrapassados. Ainda vemos países como Cuba, Venezuela e setores das autodenominadas esquerdas radicais dos países latino-americanos, muito preocupados com o que faz ou deixa de fazer o governo dos Estados Unidos, quando este país não passa de uma potência dependente, utilizando o conceito de Noam Chomsky a respeito da situação política desse país. Não há mais um protagonismo nem uma liderança, por parte dos Estados Unidos, capaz de controlar o mundo porque simplesmente não existem, pelo menos até a primeira década do século XXI, capitais nacionais capazes de exercer tal controle. O capital tornou-se volátil e pertence às corporações multinacionais que não têm nacionalidade, nem rosto, nem dono conhecido, são totalmente anônimas.

Perde-se muito tempo e esforço na América Latina com discursos antiimperialistas direcionados contra um único país ou contra um fenômeno colonizador que é a chamada globalização. O primeiro é um alvo fácil de críticas e ataques físicos porque é visível; o segundo é uma mera abstração conceitual que ninguém sabe quais são seus alcances. Os mais ortodoxos aceitam que precisam evoluir para acompanhar o ritmo da história, embora relutem contra certas transformações; outros críticos do imperialismo apresamse para entrar na globalização, mesmo que esta seja a encarnação daquilo que tanto rejeitam. A globalização não é uma coparticipação geral para o desenvolvimento conjunto da humanidade, mas constitui a entrega dos bens e valores particulares, colocando-os à disposição de quem os quiser de graça. $O$ fenômeno da globalização apresenta conseqüências indiretas para o processo 


\begin{tabular}{|l|l|l|l|l|l|l|}
\hline InterteXto & Uberaba & UFTM & $\begin{array}{l}\text { v. } 2 \\
\text { n. 3 }\end{array}$ & p. 54-76 & 2009 - jan. / jun. & ISSN 1981-0601 \\
\hline
\end{tabular}

de formação de professores de línguas quando se incorporam mecanismos de assimilação lingüística como padrões altamente valorizados ou, então, quando se desprezam os sistemas literários de maior complexidade e se adotam produtos para-didáticos em substituição da literatura mais elaborada.

Com a perspectiva de crescimento do Mercosul, ingressaram como membros integrantes do bloco, sem gozar dos benefícios dos sócios plenos, Chile e os países da CAN como Bolívia, Colômbia, Peru e Equador. Os blocos econômicos regionais e as longas discussões sobre a ALCA têm polarizado as relações entre os países Latino-americanos sendo que os elementos culturais, históricos, sociais, lingüísticos ou não têm sido abordados ou têm sido vislumbrados tangencialmente. O sonho de uma América Latina unida transformou-se em uma problemática meramente mercantil onde até 0 portonhol (mistura do Português com Espanhol), seria uma das alternativas para facilitar as relações comerciais.

Conhecendo a enorme diversidade de culturas, línguas, crenças e etnias que existem no continente africano, e confrontando essas culturas com aquilo que se dá em chamar na América Latina de afro-descendência, concluiremos que o elemento negro latino-americano não tem nada ou tem muito pouco de africano; sendo assim, esta denominação torna-se meramente referencial, já que faltam elementos identitários que permitam reunir uma comunidade composta por elementos árabes, europeus, asiáticos, africanos e os próprios componentes dos povos originários. Todavia, si os elementos componentes da cultura latino-americana são tão díspares da realidade africana, podemos supor que o objeto de luta possui um arcabouço ideológico fraco que não sustenta os ideais defendidos. A fuga da identidade latino-americana para refugiar-se numa cultura meramente referencial e totalmente desconhecida, torna falha e carente de credibilidade a empreitada dos grupos autodenominados de Afrodescendentes levando, forçosamente, a pensar todo esse movimento como jogo de interesses manipulado politicamente e cuja finalidade seria qualquer coisa, menos uma luta pela identidade e valorização cultural. 


\begin{tabular}{|l|l|l|l|l|l|l|}
\hline InterteXto & Uberaba & UFTM & $\begin{array}{l}\text { v. } 2 \\
\text { n. 3 }\end{array}$ & p. 54-76 & 2009 - jan. / jun. & ISSN 1981-0601 \\
\hline
\end{tabular}

Pensar a identidade cultural regional e local, enquanto estivermos presos aos mecanismos da chamada globalização, constitui um contra-senso e estaremos caindo na retórica dos tão surrados discursos libertários que não ultrapassam o nível de uma loquacidade anacrônica, amarga e de uma nostalgia do futuro que não sabemos se virá. Se tudo o que foi dito até aqui caracteriza mais um discurso político, histórico, sociológico do que propriamente de educação para a identidade pela valorização da língua e da cultura é porque essa realidade domina o presente, e ainda dominará o futuro próximo da América Latina. Reafirmar que a identidade latino-americana encontra-se em crise leva-nos a continuar acreditando que ainda existem possibilidades de desenvolvimento e construção de uma consciência de se, da mesma forma que a integração poderá tornar-se uma realidade caso seja repensado seu direcionamento. Conhecer a história e perceber o que somos hoje é fundamental para poder iniciar a construção daquilo que queremos, mas que ainda não existe. A formação econômica, política, social e cultural, assim como a integração e a identidade latino-americana são fontes importantes, assim como também o são a libertação, a estética, o ser e o nada para a elaboração de um constructo existencial fecundo.

Com o fim da Teologia da Libertação sobrevivem suas sementes, presentes em guerrilhas, sindicatos e grupos que tentam reviver os discursos adormecidos como o anti-imperialismo, o já mencionado anti-neoliberalismo, os defensores de movimentos étnicos e de gênero. Os discursos são os mesmos, somente muda o foco, e como o que está em questão são problemas tópicos e não conjunturais, não se alcança a elaborar um projeto global de integração, senão que cada vez que surge uma nova perspectiva dos conflitos, que fica em evidência, novamente perde-se o foco. Lideranças como Bolívar, Mariátegui, Dussel, Romero, Zea, Boff, assim como os defensores de uma sociolingüística que tenta evitar os "preconceitos lingüísticos", entre outros, não conseguiram fugir dos desvios provocados pelo particularismo que a ideologia política e 


\begin{tabular}{|l|l|l|l|l|l|l|}
\hline InterteXto & Uberaba & UFTM & $\begin{array}{l}\text { v. } 2 \\
\text { n. 3 }\end{array}$ & p. 54-76 & 2009 - jan. / jun. & ISSN 1981-0601 \\
\hline
\end{tabular}

econômica impõe àqueles que pretendem comandar um processo de afiançamento cultural, afinal, esta é mutável como a própria vida. A vida é cultura em transformação e seu dinamismo é imposto pela economia política e os processos lingüísticos dificilmente podem colocar-se à margem dessa realidade.

Solidão e companhia, riqueza e pobreza, trabalho e ociosidade, fama ou anonimato, viver ou morrer, estar cá ou lá são situações que nos levam a formular a pergunta: o que fiz do outro? Ou o que o outro fez de mim. Quixote ou Sancho, aparecer ou permanecer na retaguarda: "ver-se é morrer, ou matarse; e é preciso viver mesmo que seja na escuridão" (UNAMUNO, 1963, p. 20). Paradoxalmente em $A$ ignorância, de Milan Kundera, a vida na escuridão, o não ser visto é causa do esquecimento, enquanto houver presença haverá vida como recordação, o não lembrar é matar ou não ser lembrado é estar morto; enquanto para Unamuno, é a presença do outro que se torna um fardo que conduz à morte. O universo humano é integrado por polaridades em que a existência nos exige ser verdugos e vítimas e nesse constante querer desvendar o ser do outro, torna-se imperioso enterrar o mistério, deixar que seja devorado pelo esquecimento. Sofre quem quer desvendar o "outro", assim como padece quem perde sua identidade e somente consegue ver-se fora de si como se estivesse olhando para um espelho.

Dizer Tu não me incomoda porque ele permite que o Eu se descubra como um ser. No entanto, para Unamuno “a presença do 'outro' me incomoda porque não suportamos ter na nossa frente um espelho de nós mesmos, é como estar fora de si. O ver-se 'outro' é o caminho para odiar-se" (UNAMUNO, 1963, p. 28). Essa visão unamuniana vem de encontro ao pensamento hobbesiano em que o outro representa um perigo para a minha vida e, por isso, "se el uno no mata al otro, el otro habría matado al uno" (UNAMUNO, 1963, p. 26). Contudo, o conflito entre os homens, embora tenha conseqüências similares, a morte, as causas são diversas já que para o autor inglês a luta de todos contra todos origina-se na certeza natural de que tudo é de todos e, não 


\begin{tabular}{|l|l|l|l|l|l|l|}
\hline InterteXto & Uberaba & UFTM & $\begin{array}{l}\text { v. 2 } \\
\text { n. } 3\end{array}$ & p. 54-76 & 2009 - jan. / jun. & ISSN 1981-0601 \\
\hline
\end{tabular}

havendo lei que garanta o direito de propriedade, o princípio autonômico prevalecerá. Para Unamuno a causa do conflito encontra-se na incapacidade de separar o "eu" do "outro", já que se o "outro" é a minha imagem, a impossibilidade de ser "si - mesmo" gera um conflito de identidade.

É bom lembrar que para Hegel e Heidegger é justamente esse "outro" que me faz tomar consciência de mim. Mediante o processo educativo, o "Ser" torna-se sujeito pela consciência que lhe vem do "Eu" que "não-Eu" ("outro"). Unamuno afirma que mesmo em um nível metafísico, a religião apresenta Deus como o "outro do Céu", mas segundo este autor se Eu sou imagem do "outro do Céu", Eu não sei quem sou (UNAMUNO, 1963, p. 30), o "outro", a imagem, eu mesmo, ou, sou tudo isso, o que me torna Deus, já que sou imagem e esta só é reflexo do mesmo, espelho de mim mesmo; ou surge o imperativo de negar-se como modelo do "outro". Para o autor Basco "faz-se necessário não olhar-se no espelho para não matar-se, o "outro" toma meu ser, não devendo ser ele, para viver é preciso ser Eu e não Outro. A morte do Outro é a defesa de si mesmo" (UNAMUNO, 1963, p. 33). O homem como imagem de Deus é uma tese frágil da Antropologia cristã como mostra Kundera em $A$ Insustentável Leveza do Ser:

(...) naquela época compreendia espontaneamente que existia uma incompatibilidade entre a merda e Deus, e, por dedução percebia a fragilidade da tese da antropologia cristã segundo a qual o homem foi criado à imagem e semelhança de Deus. Das duas uma: ou o homem foi criado à imagem e semelhança de Deus e Deus tem intestinos, ou Deus não tem intestino e o homem não se parece com ele (KUNDERA, 1984, p. 205).

Nietzsche com a idéia de vontade de potência coloca a questão do "outro" em evidência e na definição de super-homem, caracteriza o gênero humano como dividido em pastores e ovelhas: os primeiros, à imagem de Cristo, fariam prevalecer a força sobre os outros e, as segundas seriam passivas, dominadas ou, como descreve Unamuno, o forte escolhe e seduz enquanto o fraco é 


\begin{tabular}{|l|l|l|l|l|l|l|}
\hline InterteXto & Uberaba & UFTM & $\begin{array}{l}\text { v. } 2 \\
\text { n. 3 }\end{array}$ & p. 54-76 & 2009 - jan. / jun. & ISSN 1981-0601 \\
\hline
\end{tabular}

escolhido e seduzido. A síndrome de Caim e Abel constitui uma problemática universal que ilustra desde a tradição veterotestamentária essa insolúvel relação "Eu versus Outro" que termina no fratricídio; o ódio, segundo argumenta Unamuno, surge como ódio de si mesmo quando o sujeito não sente que seja visto como "outro", quando é sempre igual: quando não se reconhece a si mesmo nos processos de auto-validação da identidade e talvez essa "síndrome de Caim e Abel" seja a maior expressão do estranhamento na América Latina.

Para falar de estranhamento nas relações humanas, torna-se preciso começar pelo apelo básico e fundamento da negação do outro que está presente nas relações de gênero:

(...) - Os homens chamam assim (seu próprio) à submissão do espírito. Vocês não reconhecem numa mulher senão a inteligência que os aplaude. É, tão repousante ... (...) - Não acha, querido, que as mulheres não se dão nunca (ou quase) e que os homens não possuem nada? É um jogo: "eu julgo que a possuo, portanto ela julga que é possuída ..." Sim? Realmente? O que vou dizer é muito mal comparado, mas não acha que é a história da rolha que se julgava muito mais importante do que a garrafa? (MALRAUX, p. 107-108).

construir uma identidade cultural, respeitando as diferenças, encontra seu maior obstáculo no cotidiano imaginário que tem como base as diferenças raciais e de gênero. Todavia, uma vez entendido o estranhamento de gênero, podem-se discutir os estranhamentos lingüísticos, religiosos, políticos, econômicos, ideológicos e culturais que podem vir a ser resolvidos a partir dos interesses e conveniências particulares. No entanto, cada vez que se tenta desconstruir as diferenças para construir uma unidade que permita o convívio social harmonioso, entram elementos como a economia política e os mass media que invertem a construção de uma comunidade uníssona e terminam por implodir o edifício da integração. A tentativa de reconstruir o desconstruído culmina com a negação do outro, porque faltam elementos sólidos que 


\begin{tabular}{|l|l|l|l|l|l|l|}
\hline InterteXto & Uberaba & UFTM & $\begin{array}{l}\text { v. 2 } \\
\text { n. } 3\end{array}$ & p. 54-76 & 2009 - jan. / jun. & ISSN 1981-0601 \\
\hline
\end{tabular}

permitam e incentivem a integração dos povos entre si; não por blocos econômicos, senão através de um processo que permita sentir que existe uma base comum que supera as negociações mercantis, e que coloque os diversos grupos sociais em um plano de unidade de valores utópico - concretos.

Bem sabe qual será a sua própria situação, quando as terras, sejam quais forem, tiverem sido legalmente arrebatadas aos possuidores. Chiang Kai-shek, ele mesmo, sabe-o, e diz que é obrigado a romper agora Quer ajudá-lo? Sim ou não? (...) Liu falou secamente, com a cabeça metida nos ombros. Fechou os olhos, abriu-os, fixou Ferral com o olho pisco do velho usurário de qualquer lugar na terra: - Quanto? - Cinqüenta milhões de dólares. (...) Ele atirou de novo: - Só para nós? Sim. (...) - Tem a certeza de que ele não ficará com o dinheiro, sem cumprir as promessas? (MALRAUX, 1972, p. 102-103).

As grandes questões sociais que estão colocadas na América Latina são basicamente as mesmas presentes em todos os países da terra: crises econômicas, guerras étnicas e religiosas, conflitos comerciais, violação dos Direitos Humanos, comunicação invasiva e dominação do pensamento, controle de fronteiras territoriais, dominação lingüística e lutas políticas são somente algumas das problemáticas de maior presença no mundo e às quais a América Latina não pode se subtrair:

(...) Encostou-se à parede, cuja esquina os protegia a todos, retomando pouco a pouco a respiração, pensando no prisioneiro cujas cordas cortara. "Devia ter deixado aquele tipo. Para que ter ido cortar-lhe as cordas, o que nada podia modificar?" Ainda agora, seria capaz de não ver esse homem que se debatia, amarrado, com a perna arrancada? Por causa da sua própria ferida (de Tchen), pensou em Tan Yen-ta. Como tinha sido idiota toda a noite, toda a manhã! Nada era mais simples do que matar. (...) No posto, os destroços continuavam a arder, os feridos continuavam a berrar ante a aproximação das chamas (...) (MALRAUX, 1972, p. 91).

Nascer e morrer, dar vida e tirá-la, dominar e ser dominado, ser eu e ser outro, vítima ou carrasco, prazer e dor, eis algumas das antinomias em que o homem 


\begin{tabular}{|l|l|l|l|l|l|l|}
\hline InterteXto & Uberaba & UFTM & $\begin{array}{l}\text { v. 2 } \\
\text { n. 3 }\end{array}$ & p. 54-76 & 2009 - jan. / jun. & ISSN 1981-0601 \\
\hline
\end{tabular}

se debate; o "ser" plural é próprio da natureza humana e, daí, surgem grande parte dos conflitos ligados à identidade e reconhecimento de si e aceitação do outro que serve como matéria prima nos processos educativos que visam a construção da cidadania e a afirmação dos valores de cada cultura com respeito à dignidade dos elementos presentes em segmentos diversos da sociedade.

\section{Referências}

CHOMSKY, Noam. Reflexões sobre a linguagem. São Paulo: Cultrix, 1980.

FLAUBERT, Gustav. Madame Bovary. São Paulo: Nova Cultural, 2003.

HEGEL, Friedrich. Fenomenologia do espírito. Petrópolis: Vozes, 1992.

HEIDEGGER, Martin. Arte y poesia. México: Fondo de Cultura Económica, 1978.

. Ser e Verdade: a questão fundamental da filosofia; da essência da verdade. Petrópolis: Vozes; Bragança Paulista: Editora universitária São Francisco, 2007.

KUNDERA, Milan. A arte do romance. São Paulo: Nova Fronteira, 1988. , Milan. A insustentável leveza do ser. São Paulo: Círculo do Livro, 1984.

MALRAUX, André, A Condição Humana, São Paulo: Abril Cultural, 1972.

NIETZSCHE, F. Sobre verdade e mentira no Sentido extra-moral. São Paulo: Nova Cultura, 1999.

UNAMUNO, Miguel de, El Outro. 2 ed., Madrid: Espasa - Calpe, 1964. 